\title{
Knowledge and Healthcare Seeking Behavior of Tuberculosis Patients attending Gimbi General Hospital, West Ethiopia
}

\author{
Asmamaw Abayneh Badane $^{2}$, Mohammed Gebre Dedefo ${ }^{1 *}$, Edao Sado \\ Genamo$^{1}$, Nigatu Addisu Bekele ${ }^{3}$
}

\footnotetext{
OPEN ACCESS

Citation: Asmamaw Abayneh Badane, Mohammed Gebre Dedefo, Edao Sado Genamo, Nigatu Addisu Bekele. Knowledge and Healthcare Seeking Behavior of Tuberculosis Patients attending Gimbi General Hospital, West. Ethiop J Health Sci.2018;28(5):529 doi:http://dx.doi.org/10.4314/ejhs.v28i5.3 Received: January 2, 2018 Accepted: January 3, 2018

Published: September 1, 2018

Copyright: ( $) 2018$ Asmamaw Abayneh, et al. This is an open access article distributed under the terms of the Creative Commons Attribution License, which permits unrestricted use, distribution, and reproduction in any medium, provided the original author and source are credited.

Funding: Nil

Competing Interests: The authors declare that this manuscript was approved by all authors in its form and that no competing interest exists. Affiliation and Correspondence:

${ }^{1}$ Department of Pharmacy, Wollega University, Nekemte, Ethiopia

${ }^{2}$ Jinka General Hospital, Jinka, Ethiopia

${ }^{3}$ Department of Pharmacy, Dilla

University, Dilla, Ethiopia

*Email:

mohamedg@wollegauniversity.edu.et
}

\section{ABSTRACT}

BACKGROUND: Tuberculosis (TB) now ranks alongside HIV (Human Immunodeficiency Virus) as a leading cause of death worldwide. Globally, 9.6 million people were estimated to have fallen ill with TB in 2014. The aim of this study is to assess the knowledge and healthcare seeking behaviour of tuberculosis patents in Gimbi General Hospital, West Ethiopia.

METHODS: A cross sectional study was conducted among tuberculosis patients from March 8 to April 30, 2015. The data collection method was face-to-face interview through structured standard questionnaire. To identify the factors associated with knowledge about TB and healthcare seeking behavior, backward logistic regression analysis was used.

RESULTS: Of the 138 TB patients, 85(61.6\%) had good knowledge about TB while 53(38.4\%) had poor knowledge about TB. On multivariable logistic analysis, poor knowledge about TB was more likely to occur among $T B$ patients in intensive treatment phase (Adjusted odds ratio $(A O R)=4.1,95 \% C I=1.7-9.6, p=0.001)$.

CONCLUSION: TB patients had good knowledge on signs and symptoms of $T B$, transmission of $T B$ and healthcare seeking behaviour of TB, but their knowledge on the cause of TB, treatment of $T B$ and prevention of $T B$ were not adequate. This study also revealed that the health careseeking behaviour of TB patients were good.

KEYWORDS: Tuberculosis, Knowledge, Healthcare seeking, Gimbi, Ethiopia

\section{INTRODUCTION}

Tuberculosis (TB) is an infectious disease caused by the bacillus Mycobacterium tuberculosis. It typically affects the lungs (pulmonary TB) but can affect other sites as well (extrapulmonary TB). The disease is spread in the air when people who are sick with pulmonary TB expel bacteria, for example by coughing $(1,2)$. Overall, a relatively small proportion $(5-15 \%)$ of the estimated $2-3$ billion people infected with $M$. tuberculosis develop TB disease during their lifetime (2). 
Tuberculosis now ranks alongside HIV (Human Immunodeficiency Virus) as a leading caused of death worldwide. HIV death toll in 2014 was estimated at 1.2 million, which included the 0.4 million TB deaths among HIV positive people. Worldwide, 9.6 million people were estimated to have fallen ill with TB in 2014: 5.4 million men, 3.2 million women and 1.0 million children (2).

Different studies in Bangladesh and India showed that knowledge about cause and treatment of tuberculosis among TB patients was good; however, there are poor and misconceptions about TB transmission $(3,4)$. A study done in China indicated that knowledge and awareness of TB are still unsatisfactory in rural Chinese population. Compared with men, women have less knowledge on the current TB service policy and reluctant to actively acquire information about TB (5).

In Africa, a study done in South Africa and Nigeria showed that higher levels of education and income are associated with better TB knowledge $(6,7)$. A study done in North East Libya revealed that knowledge towards TB within the population is poor (8).

Different studies showed that even though there are sufficient anti-TB drugs because of some reasons the community is not seeking care in health centers or TB services $(9,10,11)$. The reasons of the community are like, "it is difficult to get medical care there", "I thought my problem would not be solved there", "I don't know where is the health center I should go", and "I did not know I could seek a health center for this problem" $(9,10,11)$.

In Ethiopia, the 2015 WHO (World Health Organization) report showed that Ethiopia is one of the nine high TB burden countries alongside of Brazil, Cambodia, China, India, Myanmar, the Philippines, Uganda and Viet Nam and one of the three high MDR-TB (Multiple Drug Resistance Tuberculosis) burden countries alongside of Estonia and Myanmar (2).

Understanding better the level of knowledge and healthcare seeking with regard to TB helps care provider and administrator to identify the gap and to take relevant action. Thus, the purpose of this study is to assess the level of knowledge and healthcare seeking of TB patients who are currently under treatment in Gimbi General Hospital (GGH).

\section{METHODS}

Study setting and period: The study was conducted in Gimbi General Hospital (GGH), Gimbi Town, Western Wollega Zone, Oromia Region, Western Ethiopia, which is found at $421 \mathrm{~km}$ from Addis Ababa, the capital city of Ethiopia. GGH has different departments and wards like Outpatient Department (OPD), medical ward, gynecology and obstetrics ward, pediatrics ward and surgical ward. It delivers diversified health services and clinics including the emergency services, mother and child health $(\mathrm{MCH})$, laboratory and follow-up of chronic disease. The study was conducted from March 8 to April 30, 2015.

Study design: A facility based analytical cross sectional study design was used.

Study population: The study population was all TB patients who were aged 15 years and above attending in GGH during study period. All TB patients who fulfilled inclusion criteria and willing to participate in the study were included.

Data collection instrument: The questionnaire was adapted from review of different literature in English language, and it was translated into Afan Oromo and Amharic and it was again back translated into English. Comparisons were made on the consistency of two versions. The questionnaire was further modified after pretest was conducted before the actual data collection.

Data collection process and quality assurance: Data were collected using pre-tested interviewer administered structured questionnaires which was composed of mostly closed ended questions. Data collection method was face-to-face interview to get direct information from respondents. Data collection was conducted following appropriate training of the data collectors and continuous advices to keep the quality of the data. Close supervision was made by the investigators and the collected data were checked for completeness every day.

Data analysis and interpretation: After data collection, data were entered into the Statistical Package for the Social Sciences (SPSS) version 20 for analysis. Odds ratio with $95 \%$ confidence interval, along with binary and multiple logistic

DOI: http://dx.doi.org/10.4314/ejhs.v28i5.3 
regression, was used to assess the significance and strength of association. All factors with a p-value $<0.25$ in the bivariable logistic regression analysis were further entered into the multivariable model to control confounding effects. In multiple logistic regression, a p-value $<0.05$ was used as statistically significant.

Knowledge of TB patients about tuberculosis: It was measured in two categories: overall knowledge and five sub-classes of knowledge of TB. The overall knowledge of the study participants about TB was assessed using the following 10 main questions: (1) ability to mention bacteria as a cause of TB, (2) ability to mention the correct sign/symptoms of TB, (3) ability to classify TB as a transmissible disease, (4) ability to determine correct mode of transmission of TB, (5) knowing that $\mathrm{TB}$ is curable, (6) knowledge of the consequences of TB if not treated, (7) knowledge about duration of treatment of TB, (8) knowing that anti-TB drugs has side effects, (9) knowing that TB is preventable, and (10) ability to enumerate correct preventive methods of TB. Each question was rated in such a way that a score of one was given to correct responses and a score of zero was used for incorrect/'don't know' responses. Then, the responses to these questions were added together to generate a knowledge score ranging from 0 to 28 . Finally, the composite score was dichotomized using mean (which was 16.23) as a cut-off value so that score above mean value was coded as 1 showing high overall knowledge of $\mathrm{TB}$, and score below mean value was coded as 0 showing low overall knowledge of TB. Similarly, scores were generated for the five sub-classes of knowledge of TB (cause, signs/symptoms, mode of transmission, effective treatment and preventive methods of the disease) and categorized into high and low knowledge of each domain using mean value.

Healthcare seeking behaviors of TB patients: It was measured by using the answers for the following 3 questions: (1) TB patients thought on the benefit of getting early treatment, (2) if the TB patients return again to seek advice or treatment from health care providers, (3) whether TB patients visited traditional/local healer. An answer consistent with the correct healthcare seeking behaviors with regards to the disease was scored with one point, and incorrect answer was scored with zero point. Then, the responses to these questions were added together to generate a practice score ranging from 0 to 3 .
Finally, the composite score was dichotomized using mean (which was 2.86) as a cut-off value. Then, score above mean value was coded as 1 showing good healthcare seeking behavior and score below mean value was coded as 0 showing poor health care seeking behavior.

\section{RESULTS}

Socio-demographic characteristic of TB patients: During 52 days of data collection, a total of $138 \mathrm{~TB}$ patients were interviewed out of 146, giving a response rate of $94.5 \%$. Of the $138 \mathrm{~TB}$ patients, the ajority $(67.4 \%)$ were males, $69.6 \%$ of the patients were $\leq 40$ years of age, $55.8 \%$ were from rural, $37.7 \%$ were unemployed, $27.5 \%$ were illiterate and $53.6 \%$ were in continuation phase of treatment (Table 1).

Table 1: Patient characteristics and treatment phase of TB patients in Gimbi General Hospital, West Ethiopia, from March 8 to April 30, 2015.

\begin{tabular}{lcc}
\hline Variables & Frequency & $\begin{array}{c}\text { Percentage } \\
\mathbf{\%}\end{array}$ \\
\hline Sex & & \\
$\quad$ Male & 93 & $67.4 \%$ \\
$\quad$ Female & 45 & $32.6 \%$ \\
Age & & \\
$\quad \leq 40$ & 96 & $69.6 \%$ \\
$\quad>40$ & 42 & $30.4 \%$ \\
Residence & & \\
$\quad$ Urban & 61 & $44.2 \%$ \\
$\quad$ Rural & 77 & $55.8 \%$ \\
Occupation & & \\
$\quad$ Unemployed & 52 & $37.7 \%$ \\
$\quad$ Farmer & 47 & $34.1 \%$ \\
$\quad$ Employed & 39 & $28.3 \%$ \\
Educational status & & \\
$\quad$ Illiterate & 38 & $27.5 \%$ \\
$\quad$ Elementary & 41 & $29.7 \%$ \\
$\quad$ Secondary & 39 & $28.3 \%$ \\
$\quad$ College/University & 20 & $14.5 \%$ \\
Treatment phase & & \\
$\quad$ Intensive phase & 64 & $46.4 \%$ \\
$\quad$ Continuation & 74 & $53.6 \%$ \\
phase & & \\
\hline
\end{tabular}


Knowledge of TB patients: Of the 138 TB patients, 90(65.2\%) correctly answered the question about the cause of TB by saying that the cause is bacteria, and $48(34.8 \%)$ of the respondents incorrectly answered the cause of TB. Knowledge about signs and symptoms of TB was scored out of 6 , and the mean was calculated and respondents who scored above a mean value which is 3.97 is considered as knowledgeable about signs and symptoms of TB. Accordingly, $102(73.9 \%)$ of the respondents had good knowledge about signs and symptoms of TB, while $36(26.1 \%)$ had poor knowledge about signs and symptoms of TB. The majority of the respondents knew that TB has signs and symptoms of cough (94.9\%), fever (83.3\%), night sweating $(72.5 \%)$, blood stained sputum $(67.4 \%)$ and weakness (62.3\%). Only $16.7 \%$ of the respondents knew that $\mathrm{TB}$ has a sign and symptom of enlargement of lymph nodes (Table 2).

Regarding knowledge about transmission of TB, 103(74.6\%) respondents correctly answered above the mean value (which is 3.72 ) out of the 8 scores, and $35(25.4 \%)$ of them answered below the mean value. The majority of the patients, $111(80.4 \%)$, knew that TB is a transmittable disease, and the majority of the respondents know that TB is transmitted by coughing $(94.6 \%)$ and sneezing $(64.9 \%)$. The majority of the patients wrongly answered that TB is transmitted by sharing the same utensils $(72.1 \%)$ and sleeping together (64.0\%) (Table 2).

Regarding knowledge about treatment of $\mathrm{TB}$, the responses were scored out of 7 , and values above the mean (5.47) were considered as good knowledge about treatment of TB. Accordingly,
$80(58.0 \%)$ of the respondents had good knowledge about the treatment of TB while $58(42.0 \%)$ had poor knowledge about treatment of TB. All of the respondents knew that TB is a curable disease, and the majority of the patients $(82.6 \%)$ knew that they may die if they did not take TB treatment, but only $41.3 \%$ of them knew that they transmit the disease to others if they did not take TB treatment. The majority of the respondents, $112(81.2 \%)$, knew that TB is treated for 6 months and $75(54.3 \%)$ the patients answered that anti-TB drugs have side effects while $63(45.7 \%)$ of them responded that anti-TB drugs have no side effects (Table 2).

With respect to knowledge about prevention of TB, the responses were scored out of 6 , and values above the mean (2.70) were considered as good knowledge about prevention of TB. Accordingly, 82(59.4\%) of the respondents had good knowledge about the prevention of TB and $56(40.6 \%)$ had poor knowledge about prevention of TB. The majority of the respondents, $116(84.1 \%)$, knew that TB is a preventable disease and $86.2 \%$ of the respondents answered that TB can be prevented by avoiding direct coughing and breathing, but $76(65.5 \%)$ of them wrongly answered by saying TB can be prevented by using separate utensils. Only $27(23.3 \%)$ of the respondents knew that there is a vaccine for prevention of TB (Table 2). As indicated in the methods section, the overall knowledge mean score about TB was 16.23 . Of the $138 \mathrm{~TB}$ patients, $85(61.6 \%)$ had good knowledge about TB while $53(38.4 \%)$ had poor knowledge about TB (Table 2). 
Table 2: knowledge of TB patients about the etiology, signs and symptoms, transmission, treatment and prevention of TB in Gimbi General Hospital, West Ethiopia, from March 8 to April 30, 2015.

\begin{tabular}{|c|c|c|}
\hline Variables & Frequency & Percentage \% \\
\hline \multicolumn{3}{|l|}{ Causes of TB } \\
\hline Cursing from God & 18 & $13.0 \%$ \\
\hline Bacteria & 90 & $65.2 \%$ \\
\hline Virus & 16 & $11.6 \%$ \\
\hline Do not know & 14 & $10.1 \%$ \\
\hline \multicolumn{3}{|l|}{ Knowledge about cause of TB } \\
\hline Good & 90 & $65.2 \%$ \\
\hline Poor & 48 & $34.8 \%$ \\
\hline \multicolumn{3}{|l|}{ Signs and symptoms of TB } \\
\hline Cough & 131 & $94.9 \%$ \\
\hline Blood stained sputum & 93 & $67.4 \%$ \\
\hline Fever & 115 & $83.3 \%$ \\
\hline Weakness (easily fatigability) & 86 & $62.3 \%$ \\
\hline Night sweating & 100 & $72.5 \%$ \\
\hline Enlargement of lymph nodes & 23 & $16.7 \%$ \\
\hline Do not know & 5 & $3.6 \%$ \\
\hline \multicolumn{3}{|l|}{ Knowledge about signs and symptoms of TB } \\
\hline Good & 102 & $\mathbf{7 3 . 9 \%}$ \\
\hline Poor & 36 & $26.1 \%$ \\
\hline Transmission of TB & & \\
\hline \multirow{2}{*}{$\begin{array}{ll}\text { Is TB transmitted? } & \text { Yes } \\
& \text { No }\end{array}$} & 111 & $80.4 \%$ \\
\hline & 27 & $19.6 \%$ \\
\hline \multicolumn{3}{|l|}{ Mode of transmission } \\
\hline Sneezing & 72 & $64.9 \%$ \\
\hline Coughing & 105 & $94.6 \%$ \\
\hline Kissing & 30 & $27.0 \%$ \\
\hline Talking & 30 & $27.0 \%$ \\
\hline Using the same utensils & 80 & $72.1 \%$ \\
\hline Sleeping together & 71 & $64.0 \%$ \\
\hline Drinking raw milk & 14 & $12.6 \%$ \\
\hline Knowledge about transmission of TB & & \\
\hline Good & 103 & $74.6 \%$ \\
\hline Poor & 35 & $25.4 \%$ \\
\hline Treatment of TB & & \\
\hline Is TB curable? Yes & 138 & $100.0 \%$ \\
\hline No & 0 & $.0 \%$ \\
\hline What will happen if you don't take TB treatr & & \\
\hline I can lead normal life & 1 & $0.7 \%$ \\
\hline I will be cured by the help of God & 18 & $13.0 \%$ \\
\hline I may die & 114 & $82.6 \%$ \\
\hline I can transmit the disease to others & 57 & $41.3 \%$ \\
\hline For how long TB treatment is given? & & \\
\hline 2 months & 8 & $5.8 \%$ \\
\hline 4 months & 8 & $5.8 \%$ \\
\hline 6 months & 112 & $81.2 \%$ \\
\hline Do not know & 10 & $7.2 \%$ \\
\hline & 75 & $54.3 \%$ \\
\hline Do TB drugs have side effects? Yes & 63 & $45.7 \%$ \\
\hline No & & \\
\hline
\end{tabular}

DOI: http://dx.doi.org/10.4314/ejhs.v28i5.3 


\begin{tabular}{|c|c|c|}
\hline \multicolumn{3}{|l|}{ Knowledge about treatment of TB } \\
\hline Good & 80 & $58.0 \%$ \\
\hline Poor & 58 & $42.0 \%$ \\
\hline \multicolumn{3}{|l|}{ Prevention of TB } \\
\hline \multicolumn{3}{|l|}{ Is TB preventable? } \\
\hline No & 22 & $15.9 \%$ \\
\hline \multicolumn{3}{|l|}{ How TB can be prevented? } \\
\hline Vaccination & 27 & $23.3 \%$ \\
\hline Using separate utensils & 76 & $65.5 \%$ \\
\hline Avoid direct coughing and breathing & 100 & $86.2 \%$ \\
\hline Drinking boiled milk & 44 & $37.9 \%$ \\
\hline Avoid kissing & 20 & $17.2 \%$ \\
\hline \multicolumn{3}{|l|}{ Knowledge about prevention of TB } \\
\hline Good & 82 & $59.4 \%$ \\
\hline Poor & 56 & $40.6 \%$ \\
\hline \multicolumn{3}{|l|}{ Knowledge about TB } \\
\hline Good & 85 & $61.6 \%$ \\
\hline Poor & 53 & $38.4 \%$ \\
\hline
\end{tabular}

Health care seeking behavior of TB patients: Mean score of healthcare seeking behavior of TB patients was 2.86. Of the 138 respondents, $118(85.5 \%)$ had good healthcare seeking behavior about TB while $20(14.5 \%)$ of the respondents had poor healthcare seeking behavior. Most of the
Respondents, 135(97.8\%) think that getting early treatment is beneficial for people who are sick. Only $11(7.9 \%)$ of the respondents visited traditional/local healers prior to visiting healthcare unit (Table 3).

Table 3: Health care seeking behavior of TB patients in Gimbi General Hospital, West Ethiopia, from March 8 to April 30, 2015.

\begin{tabular}{|c|c|c|}
\hline Variables & Frequency & Percentage \% \\
\hline \multicolumn{3}{|c|}{$\begin{array}{l}\text { Do you think that getting early treatment is } \\
\text { beneficial for people who are sick? }\end{array}$} \\
\hline Yes & 135 & $97.8 \%$ \\
\hline No & 3 & $2.2 \%$ \\
\hline \multicolumn{3}{|c|}{$\begin{array}{l}\text { Would you return again to seek advice or } \\
\text { treatment from this care provider? }\end{array}$} \\
\hline Yes & 128 & $92.8 \%$ \\
\hline No & 10 & $7.2 \%$ \\
\hline \multicolumn{3}{|c|}{$\begin{array}{l}\text { Have you visited traditional/local healers' prior } \\
\text { to health care unit? }\end{array}$} \\
\hline Yes & 11 & $7.9 \%$ \\
\hline No & 127 & $92.1 \%$ \\
\hline \multicolumn{3}{|l|}{ Health care seeking behavior } \\
\hline Good & 118 & $85.5 \%$ \\
\hline Poor & 20 & $14.5 \%$ \\
\hline
\end{tabular}

DOI: http://dx.doi.org/10.4314/ejhs.v28i5.3 
Determinants of knowledge about TB: The bivariable analysis showed that knowledge about TB was significantly associated with sex, residence, occupation, educational status and treatment phase with a p-value $<0.05$. However, age did not show a significant association with knowledge about TB (Table 4).

Variables like sex, age, residence, occupation, educational status and treatment phase with a p-value $<0.25$ in bivariable analysis were entered into multivariable analysis. In multivariable analysis treatment phase showed a significant association with knowledge about TB with $\mathrm{p}$-value $<0.05$. Patients in intensive treatment phase were 4.1 times more likely to have poor knowledge about TB than patients who were in continuation treatment phase $(\mathrm{AOR}=4.1,95 \% \mathrm{CI}=$ 1.7-9.6, $\mathrm{p}=0.001)$ (Table 4).

Table 4: Logistic regression analysis of factors associated with knowledge of TB patients in Gimbi General Hospital, West Ethiopia, from March 8 to April 30, 2015

\begin{tabular}{|c|c|c|c|c|c|}
\hline \multirow[t]{2}{*}{ Variables } & \multirow[t]{2}{*}{ Categories } & \multicolumn{2}{|c|}{$\begin{array}{c}\text { Knowledge about } \\
\text { TB }\end{array}$} & \multirow[t]{2}{*}{$\begin{array}{c}\text { COR }(95 \% \mathrm{CI}) \\
\text { value }\end{array}$} & \multirow[t]{2}{*}{$\begin{array}{l}\text { AOR }(95 \% \\
\text { value }\end{array}$} \\
\hline & & Good & Poor & & \\
\hline \multirow[t]{2}{*}{ Sex } & Male & 64 & 29 & 1 & 1 \\
\hline & Female & 21 & 24 & 2.5(1.2-5.2) $\mathrm{P}=0.013$ & 2.4(0.9-6.3) $\mathrm{P}=0.064$ \\
\hline \multirow[t]{2}{*}{ Age } & $\leq 40$ & 64 & 32 & 1 & \\
\hline & $>40$ & 21 & 21 & $2.0(0.9-4.2) \mathrm{P}=0.066$ & --- \\
\hline \multirow[t]{2}{*}{ Residence } & Urban & 47 & 14 & 1 & 1 \\
\hline & Rural & 38 & 39 & $3.4(1.6-7.3) \mathrm{P}=0.001$ & $2.3(0.9-5.7) \mathrm{P}=0.080$ \\
\hline \multirow[t]{3}{*}{ Occupation } & Unemployed & 26 & 26 & $5.5(2.0-15.3) \mathrm{P}=0.001$ & -- \\
\hline & Farmer & 26 & 21 & $4.4(1.6-12.6) \mathrm{P}=0.005$ & --- \\
\hline & Employed & 33 & 6 & 1 & \\
\hline \multirow{4}{*}{$\begin{array}{l}\text { Educational } \\
\text { status }\end{array}$} & Illiterate & 11 & 27 & $13.9(3.4-57.2)=0.000$ & $4.5(0.9-22.0) \mathrm{P}=0.063$ \\
\hline & Elementary & 24 & 17 & $4.0(1.0-15.9) \mathrm{P}=0.048$ & $1.7(0.4-7.8) \mathrm{P}=0.480$ \\
\hline & Secondary & 33 & 6 & $1.0(0.2-4.6) \mathrm{P}=0.969$ & $0.5(0.1-2.5) \mathrm{P}=0.375$ \\
\hline & College/University & 17 & 3 & 1 & 1 \\
\hline \multirow[t]{2}{*}{$\begin{array}{l}\text { Treatment } \\
\text { phase }\end{array}$} & Intensive phase & 27 & 37 & $5.0(2.4-10.4) \mathrm{P}=0.000$ & $\begin{array}{l}4.1(1.7-9.6) \\
P=0.001\end{array}$ \\
\hline & Continuation phase & 58 & 16 & 1 & 1 \\
\hline
\end{tabular}

COR: Crude odds ratio, AOR: Adjusted odds ratio

Determinants of health care seeking behavior about TB: The bivariable analysis showed that healthcare seeking behavior about TB was significantly associated with residence and treatment phase with a p-value $<0.05$. However, sex, age, occupation, educational status and knowledge about TB did not show a significant association with healthcare seeking behavior about TB (Table 5).

Variables like residence, occupation and treatment phase with a p-value $<0.25$ in bivariable analysis were entered into multivariable analysis. In multivariable analysis, treatment phase showed a significant association with healthcare seeking behavior about TB with $p$-value $<0.05$. Patients in intensive treatment phase were 30.8 times more likely to have poor healthcare seeking behavior about TB than patients who were in continuation treatment phase $(\mathrm{AOR}=30.8,95 \% \mathrm{CI}=4.0-238.2$, $\mathrm{p}=0.001)$ (Table 5). 
Table 5: Logistic regression analysis of factors associated with health care seeking behavior of TB patients in Gimbi General Hospital, West Ethiopia, from March 8 to April 30, 2015.

\begin{tabular}{|c|c|c|c|c|c|}
\hline \multirow[t]{2}{*}{ Variables } & \multirow[t]{2}{*}{ Categories } & \multicolumn{2}{|c|}{$\begin{array}{c}\text { Health care } \\
\text { seeking behavior } \\
\text { about TB }\end{array}$} & \multirow[t]{2}{*}{ COR $(95 \%$ CI $) \quad P$ value } & \multirow[t]{2}{*}{ AOR $(95 \% \mathrm{CI}) \mathrm{P}$ value } \\
\hline & & Good & Poor & & \\
\hline \multirow[t]{2}{*}{ Sex } & Male & 79 & 14 & 1.2(0.4-3.2) $\mathrm{P}=0.788$ & --- \\
\hline & Female & 39 & 6 & 1 & \\
\hline \multirow[t]{2}{*}{ Age } & $\leq 40$ & 81 & 15 & 1.4(0.5-4.1) $\mathrm{P}=0.569$ & --- \\
\hline & $>40$ & 37 & 5 & 1 & \\
\hline \multirow[t]{2}{*}{ Residence } & Urban & 57 & 4 & 1 & \\
\hline & Rural & 61 & 16 & 3.7(1.2-11.8) $\mathrm{P}=0.025$ & --- \\
\hline \multirow[t]{3}{*}{ Occupation } & Unemployed & 46 & 6 & $1.6(0.4-6.7) \mathrm{P}=0.546$ & --- \\
\hline & Farmer & 36 & 11 & 3.7(0.9-14.3) $\mathrm{P}=0.061$ & --- \\
\hline & Employed & 36 & 3 & 1 & \\
\hline \multirow{2}{*}{$\begin{array}{l}\text { Treatment } \\
\text { phase }\end{array}$} & Intensive phase & 45 & 19 & $30.8(4.0-238.2) \mathrm{P}=0.001$ & $30.8(4.0-238.2) \mathrm{P}=0.001$ \\
\hline & Continuation phase & 73 & 1 & 1 & 1 \\
\hline \multirow{2}{*}{$\begin{array}{l}\text { Knowledge } \\
\text { about TB }\end{array}$} & Good & 75 & 10 & 1 & \\
\hline & Poor & 43 & 10 & $1.7(0.7-4.5) \quad \mathrm{P}=0.253$ & --- \\
\hline
\end{tabular}

COR: Crude odds ratio

AOR: Adjusted odds ratio

\section{DISCUSSION}

This study assessed the level of knowledge about TB and healthcare seeking behavior of TB patients. In our study, $65.2 \%$ of the respondents knew that TB is caused by bacteria which is higher than studies from Southwest Ethiopia (12), South Sudan (13), Nigeria (14) and Indies $(15,16)$ which showed lower knowledge about the cause of TB: $33.7 \%, 19.6 \%, 36 \%, 13.2 \%$ and $6.9 \%$ respectively. Even though the majority knew the cause of TB, still $34.8 \%$ of the respondents did not knw the cause of TB. This indicates that health education on the cause of TB should be given for the TB patients and the community.

In this study, the respondents' knowledge about signs and symptoms of TB were $73.9 \%$ which is comparable to the study done in Zambia (17) that reported $70 \%$ of TB patients know about sign and symptoms of TB. However, this finding is higher than the studies done in South Sudan (13) and India (16) that reported as $48 \%$ and $47 \%$ of respondents respectively know about signs and symptoms of TB. The improved knowledge about signs and symptoms of respondents in this study as compared to previous studies could be because of better opportunity to access to information.

Regarding knowledge about transmission of TB, our study revealed that $74.6 \%$ of the respondents have knowledge about transmission of TB. The finding of this study is comparable with the finding of a study done in South Sudan (13) which reported knowledge of transmission as $79.4 \%$, but higher than that of study done in India (16) which reported $30.6 \%$.

In this study, the overall knowledge of the respondents about $\mathrm{TB}$ was $61.6 \%$ which is higher than the study done in Nigeria, $41 \%$ (14) but lower than the study done in Thailand, 69\% (18). Knowledge of the TB patients on the cause of TB, signs and symptoms of TB, transmission of TB, treatment of TB and prevention of TB should be improved by providing health education in the 
health centres or hospitals by healthcare professionals in the community by Health Extension Workers and providing information for TB patients to use mass media.

In this study, being female, living in rural areas and being illiterate showed association with poor knowledge about TB in bivariable analysis, eventhough they failed to show significant association in multivariable analysis. Similar to this study, different studies in Tanzania (19) and Vietnam (20) showed significant association of knowledge about TB with level of education and a study done in Southwest Ethiopia (12) revealed that females had poor knowledge about TB. A study done in Tanzania (19) also reported that knowledge was better among urban patients. The reason could be the difference in continuous and equal health service, health education and access of health facility among urban and rural areas.

This study revealed that TB patients in intensive treatment phase were 4.1 times more likely to have poor knowledge about TB than TB patients who were in continuation treatment phase (AOR $=4.1,95 \% \mathrm{CI}=1.7-9.6, \mathrm{p}=0.001)$. The poor knowledge of TB patients in intensive treatment phase could be their limited exposure to healthcare professionals to gain knowledge as compared to TB patients in continuation treatment phase.

This study showed that the majority of the respondents $(92.1 \%)$ visited health unit, and only $7.9 \%$ of them visited traditional healers before visiting health unit. Unlike our study, different studies reported that lower number of respondents visited health unit prior to visiting traditional healers: $78 \%$ in Amhara Region of Ethiopia (10), $32 \%$ in Nigeria (21), $84 \%$ in South Africa (22) and $54.3 \%$ in India (23).

In this study, knowledge about TB did not show significant association with healthcare seeking behaviour. However, different studies done in Thailand (18) and Northeast Ethiopia (24) showed that knowledge was significantly associated with treatment-seeking behaviours. Patients with better knowledge of TB were more likely to come to a hospital with a TB clinic first than those with poorer knowledge. The reason for the difference could be our small sample size.
Limitations of this study was that the knowledge and healthcare seeking behaviour of TB patients were assessed based on respondents' self-report, which may lead to recall bias. The other limitation of the study was that it did not assess the delay of time to seek healthcare and reasons for delay. The sample size of this study was also small because of the short duration of the study period. This can also have impact on the significance of the variables.

In conclusion, the finding of this study showed that TB patients had good knowledge on signs and symptoms and transmission of $\mathrm{TB}$, but their knowledge on the cause of TB, treatment of $\mathrm{TB}$ and prevention of TB was not adequate. Thus, we suggest health education to be provided for TB patients in hospitals and health centres by healthcare professionals and in the community by Health Extension Workers. This study also revealed that the healthcare seeking behaviour of TB patients was good. To have improved healthcare seeking behaviour we recommend health education on knowledge about TB and importance of seeking care to have good outcome in the management of TB.

\section{REFERENCES}

1. Department of Health. Manual of Procedures of the National Tuberculosis Control Program. Manila, Republic of Philippines: DOH, 2014. $5^{\text {th }}$ edition.

2. World Health Organization (WHO): Global Tuberculosis Report 2015: Country Profiles. Switzerland: World Health Organization. 2015. $20^{\text {th }}$ edition.

3. Tasnim S, Rahman A, Hoque FMA. Patient's Knowledge and Attitude towards Tuberculosis in an Urban Setting. Hindawi Publishing Corporation, Pulmonary Medicine. 2012. doi:10.1155/2012/352850.

4. Sreeramareddy CT, Kumar HNH, Arokiasamy JT. Prevalence of self-reported tuberculosis, knowledge about tuberculosis transmission and its determinants among adults in India: results from a nation-wide cross-sectional household survey. BMC Infectious Diseases. 2013;13(16).

5. Wang J, Fei Y, Shen H, Xu B. Gender difference in knowledge oftuberculosis and associated healthcare seeking behaviors: a cross-sectional study in a rural area of China. BMC Public Health. 2008;8(354).

DOI: http://dx.doi.org/10.4314/ejhs.v28i5.3 
6. Naidoo P, Simbayi L, Labadarios D, Ntsepe Y, Bikitsha N, Khan G, et al. Predictors of knowledge about tuberculosis: results from SANHANES I, a national, cross-sectional household survey in South Africa. BMC Public Health. 2016;16(276).

7. Uchenna OU, Ngozi CJ, C. OD, C. NC, O. MA. Assessment of tuberculosis-related knowledge, attitudes and practices in Enugu, South East Nigeria. Journal of Infectious Diseases and Immunity. 2014;6(1):1-9.

8. Solliman MA, Hassali MA, Al-Haddad M, Hadida MM, Saleem F, Atif M, et al. Assessment of Knowledge towards Tuberculosis among general population in North East Libya. Journal of Applied Pharmaceutical Science. 2012;02 (04):24-30.

9. Almeida CPBd, Skupien EC, Silva DR. Health care seeking behavior and patient delay in tuberculosis diagnosis. Cad Saúde Pública, Rio de Janeiro. 2015;31(2):321-30.

10. Yimer S, Holm-Hansen C, Yimaldu T, Bjune G. Health care seeking among pulmonary tuberculosis suspects and patients in rural Ethiopia: a community-based study. BMC Public Health. 2009;9(454).

11. Engeda EH, Dachew BA, Woreta HK, Kelkay MM, Ashenafie TD. Health Seeking Behaviour and Associated Factors among Pulmonary Tuberculosis Suspects in Lay Armachiho District, Northwest Ethiopia: A Community-Based Study. Hindawi Publishing Corporation, Tuberculosis Research and Treatment. 2016. doi.org/10.1155/2016/7892701.

12. Abebe G, Deribew A, Apers L, Woldemichael K, Shiffa J, Tesfaye M, et al. Knowledge, Health Seeking Behavior and Perceived Stigma towards Tuberculosis among Tuberculosis Suspects in a Rural Community in Southwest Ethiopia. PLoS ONE. 2010;5(10):e13339. doi:10.1371/journal.pone.0013339.

13. Kenyi LJ, Martin T, Ohisa G, Matthew D, Macharia S, Joseph L. Knowledge, attitude and practice (KAP) of tuberculosis patients enrolled on treatment in Juba City, South Sudan 2010: a pilot study. South Sudan Medical Journal. 2014;7(2):2832.

14. Biya O, Gidado S, Abraham A, Waziri N, Nguku $\mathrm{P}$, Nsubuga $\mathrm{P}$, et al. Knowledge, care-seeking behavior, and factors associated with patient delay among newly-diagnosed pulmonary tuberculosis patients, Federal Capital Territory, Nigeria, 2010. Pan African Medical Journal. 2014;18(6).
15. Yadav SK, Damor R, Kantharia SL, Tiwari M. Assessment of Knowledge and Treatment Seeking Behaviour among Tuberculosis and MultiDrug Resistant Tuberculosis Patients:-A Case Control Study. IOSR Journal of Dental and Medical Sciences. 2015;14(7 ):66-71.

16. Damor R, Singh MP, Jankar D, Rathod S, Gosaliya V. Assessment of Knowledge about Tuberculosis among Newly Diagnosed Patients Registered in District Tuberculosis Center, Bhavnagar, Gujarat. NJIRM. 2012;3(3):90-4.

17. Kaona FA, Tuba M, Siziya S, Sikaona L. An assessment of factors contributing to treatment adherence and knowledge of TB transmission among patients on TB treatment. BMC Public Health. 2004;4(68).

18. Chimbanrai B, Fungladda W, Kaewkungwal J, Silachamroon U. Treatment-Seeking Behaviors and Improvement in Adherence to Treatment Regimen of Tuberculosis Patients using Intensive Triad-Model Program, Thailand. South East Asian J Trop Med Public Health. 2008;39(3):526-41.

19. Wandwalo ER, Mørkve O. Knowledge of disease and treatment among tuberculosis patients in Mwanza, Tanzania. Int $J$ Tuberc Lung Dis. 2000;4(11):1041-6.

20. Hoa NP, Diwan VK, Co NV, Thorson AEK. Knowledge about tuberculosis and its treatment among new pulmonary TB patients in the north and central regions of Vietnam. Int J Tuberc Lung Dis. 2004;8(5):603-8.

21. Christopher O, Bosede I. Health Seeking Behaviour of Tuberculosis Patients in Ekiti State, Nigeria. Ethno Med. 2010;4(3):191-7.

22. Pronyk PM, Makhubele MB, Hargreaves JR, Tollman SM, Hausler HP. Assessing health seeking behaviour among tuberculosis patients in rural South Africa. Int J Tuberc Lung Dis. 2001 5(7):619-27.

23. Kumar S, Kotresh, Amruth, Prashanth, PN N. Health seeking behaviour among tuberculosis patients registered under RNTCP Tumkur district, Karnataka. Indian Journal of Forensic and Community Medicine. 2016;3(2):146-51.

24. Tsegaye D, Abiy E, Mesele T, Tadesse T. Delay in Seeking Health Care and associated Factors among Pulmonary Tuberculosis Patients in North Wollo Zone, Northeast Ethiopia: Institution Based Crosssectional Study. Archives of Clinical Microbiology. 2016;7(3).

DOI: http://dx.doi.org/10.4314/ejhs.v28i5.3 